\title{
Dificuldades diagnósticas da causa mortis em cadáveres decompostos
}

\author{
Diagnostic difficulties regarding the cause of death in \\ decomposed cadavers
}

\author{
Aimée Christine Alcântara Ribeiro Szönyi Porto ${ }^{1}$, Ivan Dieb Miziara ${ }^{2}$
}

DOI: http://dx.doi.org/10.11606/issn.2317-2770.v24i2p57-66

Porto ACARS, Miziara ID. Dificuldades diagnósticas da causa mortis em cadáveres decompostos. Saúde, Ética \& Justiça. 2019;24(2):57-66.

RESUMO: Os autores clássicos da Medicina Legal brasileira fornecem uma base sólida para o estudo da decomposição cadavérica. Por meio da leitura de seus livros, notou-se que a marcha da decomposição é composta de fases ocorridas em períodos específicos, que podem se sobrepor ou ter seus rumos alterados por fatores que vão, desde o ambiente em que o cadáver se encontra, até sua compleição física e comorbidades em vida. Com o objetivo específico de aprender como contornar tais dificuldades durante as investigações e necropsias destes casos, foi realizado levantamento bibliográfico de artigos científicos nas bases PubMed, Scielo e Scopus, pelos unitermos Putrefied, Cadaveric Putrefaction, Diagnosis e Causa Mortis, que resultou em dez artigos em língua inglesa, publicados de 2000 a 2019, a respeito de cadáveres de seres humanos. Foi possível depreender que métodos já conhecidos pelos pesquisadores (a saber: equipamentos de imagem, histopatologia, e análises químicas de fluidos corporais), são capazes de alterar deduções feitas antes de seu uso. Entretanto, apesar de todo o auxílio que oferecem, não substituem o olhar atento de uma equipe forense bem treinada. Ao contrário, devem caminhar juntos, reforçando ainda mais a certeza de que a necropsia de um cadáver em decomposição é indispensável de ser realizada.

DESCRITORES: Biodegradação Ambiental; Cadáver; Diagnóstico; Causa de Morte.

\footnotetext{
1. Médica Residente de Medicina Legal e Perícia Médica do Departamento de Medicina Legal, Ética Médica e Medicina Social e do Trabalho da Universidade de São Paulo (FMUSP).

2. Professor associado do Departamento de Medicina Legal, Ética Médica e Medicina Social e do Trabalho da Faculdade de Medicina da Universidade de São Paulo.

Endereço para correspondência: aimee.s.porto@gmail.com
} 


\section{INTRODUÇ̃̃̃O}

A morte de um indivíduo é um processo que tem início com graduais e irreversíveis modificações no corpo. Essas alterações dependem de fatores intrínsecos, próprios da constituição anatômica e possíveis comorbidades existentes em vida, e de fatores extrínsecos, próprios do ambiente em que o cadáver permaneceu ${ }^{1-6}$.

A autólise dá início à putrefação, que possui quatro períodos fundamentais: período de coloração, gasoso, coliquativo e de esqueletização. É importante enfatizar que esses fenômenos cadavéricos putrefativos alteram características morfológicas do corpo examinado, assim como alteram características de lesões internas e externas causadas tanto por agentes lesivos mecânicos, físicos, químicos, bem como biodinâmicos ${ }^{1-6}$.

Desse modo, torna-se uma árdua tarefa a diagnose da causa mortis, quando nos defrontamos com um cadáver em avançado estado de decomposição. As transformações sofridas pelo cadáver na marcha de decomposição, como referimos anteriormente, modificam sobremaneira os aspectos físicos do cadáver, "disfarçando lesões" nas mortes violentas, ocultando sinais denunciadores de morte natural, e até a própria identificação do indivíduo ${ }^{1-6}$.

\section{OBJETIVOS}

O estudo teve por objetivos:

1) Fazer uma revisão da literatura médica disponível, a fim de analisar de que forma a putrefação cadavérica dificulta a investigação e a determinação da causa mortis e da identificação de um indivíduo em uma necropsia.

2) Explorar na literatura científica dos últimos vinte anos o que há de disponível para minimizar estas dificuldades e auxiliar a busca por corretos diagnóstico de causa mortis e identificação humana.

\section{MÉTODO}

Pesquisa bibliográfica de artigos científicos nas seguintes bases de dados: PubMed, Scielo, Scopus, resultantes das pesquisas dos unitermos Putrefied, Cadaveric Putrefaction, Diagnosis, Causa Mortis. Foram também consultados livros-texto e compêndios de Medicina Legal em língua portuguesa.

\section{Critérios de inclusão}

Artigos publicados nas bases de dados consultadas, após o ano 2000 e até 2019.

\section{Critérios de exclusão}

Artigos que não discorriam sobre a causa mortis, ou aqueles em que não haja aplicabilidade em cadáveres em estágios de decomposição, ou ainda pesquisas realizadas em cadáveres de animais.

\section{Tamanho da amostra}

Foram encontrados 74 artigos científicos, sendo então selecionados dez artigos, que obedeciam aos critérios de inclusão e exclusão.

\section{RESULTADOS}

Quando um cadáver se encontra na natureza, seja em meio terrestre ou aquático, pode receber a atuação de diversos tipos de animais, que causam lesões que podem ser confundidas com uma causa de morte, ou ainda que modificam traumatismos ocorridos em vida e que são pertinentes à investigação. $\mathrm{O}$ artigo de Byard et al. ${ }^{7}$ mostra que os animais variam desde larvas de moscas, formigas e pássaros, a cachorros, roedores e animais aquáticos como piolhos do mar e peixes. Para auxiliar na avaliação dos achados, o padrão de lesões pode nortear a identificação das espécies animais envolvidas. Outra característica importante é a ausência de reação vital nas lesões. O exame radiográfico dos animais encontrados no ambiente ou o exame de suas fezes pode auxiliar na procura por tecidos humanos ${ }^{7}$. Estes achados podem simular disparos por arma de fogo, lesões por arma branca e lesões de defesa nas mãos. A remoção da pele pode atrapalhar a avaliação de potenciais características úteis na identificação, como cicatrizes cirúrgicas e tatuagens, e a perda de órgãos internos pode atrapalhar a determinação da contribuição ou da causa efetiva de morte por alguma doença orgânica subjacente ${ }^{7}$.

A avaliação precisa das lesões ocorridas antes da morte também é dificultada se o intervalo entre a morte e o encontro do corpo for prolongado. O estado avançado de putrefação e a autólise resultam na desintegração de órgãos e tecidos, com descoloração e destruição de elementos sanguíneos. Essas alterações podem tornar a definição de lesões como as de armas brancas mais difícil e impedir a identificação de equimoses ou lesões superficiais da pele ${ }^{7}$.

Particularmente, as larvas podem criar ferimentos na pele que podem ser confundidos com lesões por instrumentos cortantes e, também, podem modificar ou mascarar lesões incisas genuínas; isto é particularmente devido à predileção das larvas por lesões já pré-existentes no corpo. Apesar dos problemas causados por infestação massiva de larvas, insetos podem ser úteis pelo DNA humano isolado e identificado nas larvas. Eles também são úteis na determinação do intervalo de morte, auxiliada pela avaliação entomológica do desenvolvimento dos estágios larvais. A presença e o alcance de insetos específicos em certos habitats também podem indicar a 
movimentação do cadáver após a morte?

Formigas também são predadores post-mortem comuns. Uma característica deixada por sua ação é a remoção dos cílios. Também são responsáveis por consideráveis danos à pele, pois as lesões resultantes podem ser confundidas com abrasões e contribuir para intensa perda de sangue pela infiltração passiva, se o dano na pele ocorreu em uma área congesta ${ }^{7}$.

As atividades animais também podem ser confundidas com homicídios envolvendo lesões bizarras, como homicidas sádicos ou ritualísticos. Um exemplo são os pássaros que costumam alimentar-se de globos oculares e infligir lesões no rosto?.

Um cenário característico desta atividade é o da pessoa idosa que mora sozinha com animais de estimação, como gatos e cachorros. As eventuais causas naturais das mortes destas pessoas podem não ser detectadas de imediato, pois os animais sentem-se famintos após algum tempo sozinhos e alimentam-se dos corpos de seus donos. Mais comumente removem os músculos da face e da cabeça, ignorando as partes cobertas por roupas; o resultado é a esqueletização da face. Podem também atingir os órgãos da cavidade torácica, podendo causar desmembramento ${ }^{7}$.

Tratando-se especificamente do ambiente aquático, muitos desafios são encontrados pela equipe de investigação forense. Como em outros casos que envolvam circunstâncias incertas, os achados da necrópsia devem ser avaliados através das informações encontradas, incluindo fatores internos e externos. Os sinais positivos de afogamento são bastante inespecíficos e desaparecem com o início da putrefação, e ferimentos letais e alterações macroscópicas que excluam afogamento tornam-se difíceis de interpretar com o passar do tempo. Estas dificuldades levam à necessidade de uma detalhada investigação nas alterações microscópicas e no desenvolvimento de métodos complementares de diagnóstico de afogamento, por exemplo o teste de diatomáceas ${ }^{8}$. Se houve ingestão de água em vida, podem ser encontradas diatomáceas em vias aéreas baixas, como pulmões, e no sangue.

No estudo de Lunetta et al. ${ }^{8}$ foram analisados 1590 corpos encontrados em água. Uma série de alterações patológicas foram analisadas (espuma externa, fluido espumoso nas vias aéreas, sobreposição das margens mediais dos pulmões, peso do exsudato pulmonar/pleural) nos cadáveres com mortes decorrentes de afogamentos testemunhados e sem sinais de putrefação, tentativas de ressuscitação ou alterações pulmonares patológicas, sendo este $\mathrm{n}=262^{8}$.

No momento da necrópsia, 590 (37,1\%) cadáveres apresentavam alguma alteração putrefativa. Foi verificado que a frequência da associação de alterações patológicas - espuma externa, fluido espumoso nas vias aéreas e sobreposição das margens mediais dos pulmões - ou a presença simultânea de espuma externa e sobreposição das margens anteriores dos pulmões diminuiu significativamente de acordo com o tempo de submersão post-mortem, ou seja, com o avançar do processo putrefativo ${ }^{8}$.

A espuma externa pode ser levada pela água, intencionalmente ou não intencionalmente removida antes da chegada do corpo ao necrotério ou pode ser subestimada por quem realiza a necrópsia, não sendo mencionada nos laudos.

$\mathrm{O}$ peso do exsudato pulmonar/pleural nos corpos que tiveram seu afogamento testemunhado era significativamente maior nos corpos frescos $(\mathrm{n}=184)$ do que nos que apresentavam alterações putrefativas $(\mathrm{n}=72)$, tratando-se então de uma característica não passível de observação em corpos em avançado estado de decomposição .

Sendo assim, depreende-se que a observação das alterações patológicas específicas do afogamento depende principalmente do tempo de submersão post-mortem e das alterações putrefativas, além do componente subjetivo de quem as analisa na cena e na sala de necrópsia ${ }^{8}$.

Como já visto, a necrópsia de um corpo em decomposição é um verdadeiro desafio aos patologistas forenses. As alterações post-mortem devido à putrefação $\mathrm{e}$ à autólise incluem dano tecidual e menor disponibilidade de matrizes biológicas9.

Entretanto, a necrópsia geralmente responde a muitas perguntas levantadas pela investigação, e pode ser uma ferramenta valiosa de prevenção, tornando possível a definição de um perfil de pessoas em risco de morrerem sozinhas .

Para avaliar e formular alguma informação que auxilie na prevenção de pessoas que morrem sozinhas e para melhor diagnóstico da causa de morte, é preferível que se saibam alguns dados antemortem, como o estado de saúde prévio, idade, sexo e isolamento social ${ }^{9}$.

Sobre os dados post-mortem, é importante saber as condições da descoberta (local e data de morte), o grau de putrefação do corpo, seu exame radiográfico, análise toxicológica, análise histopatológica, procedimento de identificação (DNA, odontológico, impressões digitais, radiografia, reconhecimento visual ou investigação policial), causa e modo da morte?

Dos 350 casos analisados no estudo de Maujean et al. ${ }^{9}$, foi observado histórico psiquiátrico em 101 casos $(28,9 \%)$; vício em $80(22,6 \%)$, sendo $89 \%$ destes relacionado a alcoolismo crônico; doença cardiovascular em 73 (20,9\%); e doença neoplásica em 20 casos (5,7\%). A maioria foi encontrada em locais fechados, sendo a maior parte destes em seus lares. $\mathrm{O}$ ambiente mais frequente foi apartamento, seguido de abrigos, casas e acomodações de trabalho. Em relação ao grau de putrefação, o maior número apresentou estado avançado. A identificação foi 
efetiva em 349 casos $(99,7 \%)$, exceto no corpo que foi encontrado em um rio. A causa da morte foi identificada em $80 \%$ dos casos; nas $70(20 \%)$ que não levaram à determinação da causa, $61(87,1 \%)$ eram corpos com avançado grau de putrefação. A maneira como a morte ocorreu foi encontrada em 313 casos $(86,6 \%)$; em 47 $(13,4 \%)$ a maneira não pôde ser especificada ${ }^{9}$.

Os corpos putrefeitos em sua maioria eram de idosos e pessoas solitárias; também podem ser associados a desordens psiquiátricas. A causa de morte mais representativa do estudo foi natural $(68 \%)$, de origem cardíaca $(46,8 \%)$. A análise histológica determinou a causa mortis em 78 casos $(22,3 \%)$. Foram utilizadas técnicas apropriadas para tecidos danificados, como o aumento da duração das fases de preparação do tecido (fixação, embebição em parafina e coloração) e o uso de lâminas pré-tratadas. No estudo, o exame histológico foi capaz de evidenciar formação de fibrina e agregado plaquetário patológico nos casos de embolia pulmonar, apesar das alterações post-mortem de putrefação, assim como ruptura de parede alveolar nos casos de afogamento e lesões horizontais ao longo da íntima das artérias carótidas nos casos de suspensão ${ }^{9}$.

Sobre a análise toxicológica, sua interpretação post-mortem é um desafio e necessita levar em conta vários elementos, como neoformação, redistribuição, difusão, diferenças sítio a sítio, artefatos, instabilidade de drogas, metabolismo ou depuração, e tolerância. Além disso, a disponibilidade de matrizes biológicas diminui progressivamente à medida em que as alterações do corpo avançam. Uma alternativa que permanece disponível por mais tempo é a medula óssea, porém exige estudo de correlação entre sua concentração ante e post-mortem com a do sangue .

Um caso ilustrativo a respeito destes fatos é o descrito no artigo de Byard et $\mathrm{al}^{10}$. Um homem de 49 anos foi encontrado morto em casa, devido à doença cardíaca isquêmica ${ }^{10}$. Havia feridas morfologicamente similares em seu abdômen, com bordas incisas limpas e sem hemorragia significativa. A aparência era mais semelhante a lesões post-mortem, ativando a suspeita de mutilação ritual ${ }^{10}$.

Subsequente exploração das feridas revelou separação da pele e do tecido subcutâneo, com fragmentos esparsos de material de sutura dentro de camadas musculares subjacentes. As feridas não se comunicavam com a cavidade abdominal, e não havia lesões em órgãos e vasos vitais. Após a remoção dos órgãos abdominais, um recente e intacto bypass protético aortobifemoral foi localizado. Havia aterosclerose de artéria coronária, e um recente infarto do miocárdio da parede anterior do ventrículo esquerdo. Não foram encontradas outras doenças que pudessem contribuir para a morte ou causá-la, e não havia evidência de trauma; não foram realizadas análises toxicológicas. Investigação posterior revelou que o falecido havia sido submetido a cirurgia de bypass aproximadamente 4 a 6 semanas antes da morte ${ }^{10}$. Concluiu-se assim que as incisões cirúrgicas foram forçadamente abertas por ruptura de tecido pela putrefação, inchaço e formação de gás ${ }^{10}$.

Outra dificuldade da medicina forense consta em fixar a hora da morte dentro dos limites da probabilidade; quanto maior o intervalo post-mortem, menos precisa será a estimativa da hora da morte. O livor mortis, como primeira alteração post-mortem identificada, é amplamente utilizado para estimar este intervalo ${ }^{11}$. Na superfície da pele, aparece como pequenas manchas cutâneas púrpura-avermelhadas, com aglutinação gradual de sangue nos vasos e leitos capilares após a cessação da circulação. A avaliação médico legal do livor é baseada em sua cor e distribuição, sendo a observação visual o método de análise mais utilizado ${ }^{11}$. Entretanto, em face da extrema subjetividade da observação e da progressão do livor, torna-se difícil realizar uma correta e rigorosa descrição da cor e do grau de hipóstase. A avaliação do branqueamento do livor por digito-pressão também depende se a intensidade da pressão exercida produziu ou não branqueamento visível ${ }^{11}$.

O estudo de Romanelli et al. ${ }^{11}$ analisou manchas de hipóstases em 101 cadáveres, em diferentes condições de temperatura e pressão. Foram utilizados um dinamômetro para mensuração da pressão, um cronômetro digital para calcular a duração da digito-pressão e um instrumento que mensura diferenças de cor baseadas em método espectral. Diferentes regiões do corpo foram analisadas, com regiões sem livor para controle, e aplicados valores crescentes de pressão e de tempo de pressão aplicada. As medidas foram realizadas com as seguintes informações conhecidas: dia e hora da mensuração, dados pessoais de cada indivíduo, dimensões do corpo, extensão das hipóstases, temperatura ambiental, umidade, causa da morte, intervalo post-mortem e tempo necessário para reenchimento após aplicação da pressão nas condições padrão ${ }^{11}$.

O livor torna-se fixo após aproximadamente 12 horas. Quando o livor ainda não está fixo, isto é demonstrado aplicando-se pressão em uma área do corpo e ocorrendo logo após o branqueamento na área; quando removida a pressão, a área branqueada é novamente preenchida com sangue. O livor pode ser considerado próximo de fixo se o branqueamento não é facilmente produzido quando a pressão é aplicada ou fixo se a digitopressão não produzir branqueamento ${ }^{11}$.

Os resultados demonstram que, caso parâmetros otimizados forem utilizados em uma investigação forense, é possível inferir uma estimativa mais objetiva de um intervalo post-mortem desconhecido, baseado em uma análise mais padronizada do livor mortis, e utilizando assim este sinal de certeza de morte como auxiliador da avaliação ${ }^{11}$. 
Porto ACARS, Miziara ID. Dificuldades diagnósticas da causa mortis em cadáveres decompostos.

Em alguns momentos, as hipóstases e outros sinais da morte podem confundir o examinador em vez de esclarecer os fatos. As alterações post-mortem podem ser percebidas e diferenciadas dos processos patológicos e das lesões na MDCT (tomografia multislice), que tem se mostrado um bom complemento à necrópsia ${ }^{12}$, como um bom exemplo de virtopsia. Exemplos ${ }^{12}$ : livor mortis aumenta a atenuação da vasculatura e tecidos na MDCT, a autólise altera a atenuação dos órgãos e a ação de insetos e animais produz alterações evidentes. Há ainda distensão do corpo, pela produção de gás que se inicia no espaço intravascular e progride para todos os espaços anatômicos, órgãos e tecidos moles ${ }^{12}$.

No estudo de Levy et al. ${ }^{12}$, os corpos foram escaneados dentro de sacos, com os braços ao lado do corpo. Foram tiradas duas séries de imagens, uma da cabeça axialmente e outra do corpo inteiro ${ }^{12}$.

$\mathrm{Na}$ MDCT, livor na vasculatura pode ser confundido com trombose; entretanto, o livor estará presente em porções dependentes de gravidade dos vasos e câmaras cardíacas, e em contraste, trombos intraluminais tipicamente terão contornos redondos ou ovais e estarão localizados em porções não dependentes de gravidade dos vasos ${ }^{12}$.

A extensão e a densidade do parênquima pulmonar são maiores em congestão venosa pulmonar e edema comparado ao livor; também o quadro patológico geralmente apresenta distribuição central em vidro fosco e ingurgitamento venoso pulmonar. As características de relevância investigativa do livor ao exame macroscópico incluem coloração, distribuição e fixação, sendo a distribuição importante para determinar se o corpo foi movido. Pode haver dificuldade para diferenciar o livor da contusão em corpos parcialmente decompostos ${ }^{12}$. Livor nos pulmões pode mimetizar consolidação pulmonar de processos infecciosos ou neoplásicos. A avaliação cuidadosa pode ser útil para diferenciar livor de processos patológicos ${ }^{12}$.

Tabela 1 - Classificação da decomposição na MDCT

\begin{tabular}{l|l|l}
\hline Recente & Moderada & Avançada \\
\hline Autólise cerebral & Colonização/liquidação cerebral & Liquefação cerebral \\
\hline Distensão abdominal & Fluido na cavidade & Gás subcutâneo difuso \\
\hline Gás mural intestinal & Gás na cavidade & Gás difuso no órgão visceral e colapso do órgão \\
\hline Gás intravascular & Pequenas quantidades de gás subcutâneo & Evidência de insetos ou predação animal \\
\hline & Pequenas quantidades de gás visceral & Esqueletização \\
\hline & & Formação de adipocera \\
\hline & & Mumificação \\
\hline
\end{tabular}

Fonte: Levy et al. ${ }^{12}, 2010$.

Um dos sinais mais recentes de decomposição é a autólise cerebral; as características na MDCT incluem borramento e perda de definição da junção da matéria cinza e branca, decréscimo da atenuação cerebral e apagamento dos sulcos e ventrículos. Neste período o cérebro pode exibir amolecimento suave, mas macroscopicamente apresentar-se normal. Durante dois ou três dias, há progressão da autólise e completa perda da diferenciação da matéria cinza e branca na MDCT e os ventrículos e sulcos tornam-se apagados. À medida em que o cérebro amolece, ele se estabelece na porção do crânio dependente de gravidade e o gás preenche a porção não dependente. Nesse estágio, gás putrefativo pode estar presente entre as estruturas vasculares e espaços intracranianos. Com a completa liquefação do cérebro, ele estará em atenuação líquida na MDCT. A parede intestinal e o sistema venoso mesentérico e portal são geralmente os primeiros locais de gás putrefativo junto aos intestinos delgado e grosso. À medida em que a decomposição progride, o gás entra nas estruturas vasculares e potenciais espaços anatômicos. O gás putrefativo está normalmente distribuído simetricamente através do corpo, a não ser que haja decomposição focal ou assimétrica de uma lesão subjacente ou causa focal de aquecimento ou resfriamento do corpo. A atenuação dos órgãos sólidos não se altera até avançados estágios de decomposição, quando os órgãos começam a se fragmentar, degenerar e liquefazer e o gás preencher as cavidades abdominais e torácicas ${ }^{12}$.

A MDCT post-mortem permite a visualização de estruturas anatômicas, padrões de lesão e localização de corpos estranhos antes da dissecação. Consequentemente, pode ser muito útil para direcionar a necrópsia do corpo putrefeito $^{12}$.

Como visto, o tecido cerebral é muito afetado pela autólise e pela putrefação. O exame do cérebro decomposto é amplamente negligenciado na neuropatologia forense. Porém, quando se utiliza a coloração de prata, que demonstra placas neuríticas, e a imunocitoquímica, para proteína precursora de beta-amiloide ( $\beta$-APP) e outras moléculas, obtêm-se resultados comparáveis com os vistos em cérebros fixados bem preservados na pesquisa 
do Alzheimer, como visto no artigo de MacKenzie ${ }^{13}$. Em casos de mumificação natural ou adipocere, o cérebro pode ser encontrado relativamente bem preservado naturalmente, embora a histologia esteja prejudicada ${ }^{13}$. O processamento padrão e o procedimento de coloração produziram resultados satisfatórios mesmo em estágios avançados de decomposição. A principal dificuldade é diferenciar alterações post-mortem de alterações patológicas genuínas ${ }^{13}$.

Seccionar o cérebro no modo tradicional de fatias coronais é uma técnica que ainda tem valor. A matéria branca frequentemente possui o padrão de "queijo suíço", devido ao supercrescimento post-mortem de bactérias e seus gases. É apropriado para garantir que a histologia será amplamente investigada, coletar áreas identificáveis como possivelmente afetadas por outros processos patológicos, como blocos de hemisfério parasagital, corpo caloso, gânglio basal e tronco cerebral para determinar presença ou não de lesão axonal difusa traumática ${ }^{13}$.

Permanecem questões ao redor da escala de tempo na qual lesão axonal é identificável por imunocitoquímica, e se a lesão axonal foi causada por trauma, por isquemia ou por outro fator. A presença de lesão axonal identificável por $\beta$-APP não equivale à evidência de lesão contusa na cabeça. Entretanto, interpretação cuidadosa do padrão de coloração $\beta$-APP no contexto de outras caracterizações patológicas pode permitir diferenciação entre uma causa traumática e uma vascular. Também, a presença de lesão axonal identificável por imunocitoquímica $\beta$-APP indica que houve sobrevida por um tempo após o golpe que levou à lesão axonal. $\mathrm{O}$ achado frisado positivo de $\beta$-APP de axônios ou esferoides em áreas vulneráveis ao trauma, como a matéria branca parasagital, esplênio do corpo caloso e ponte rostral, sem características sugestivas de causa vascular, é consistente com a ocorrência de um trauma craniano contuso e sobrevivência por um tempo curto (35 minutos ou mais) após a lesão; nos casos criminais pode sugerir que a lesão não foi imediatamente fatal. Proteína precursora de beta-amiloide também pode mostrar coloração neuronal forte, que pode ser uma manifestação de lesão cerebral traumática ou lesão hipóxica-isquêmica no período ante-mortem imediato ${ }^{13}$.

O escopo do estudo de Cattaneo et al. ${ }^{14}$ foi coletar fraturas em ossos de cadáveres com o tempo sabido de sobrevivência entre o trauma e a morte, e submetê-los a procedimento simulado de putrefação até tornarem-se ossos secos ou macerados, e então realizar análises macro e microscópicas para verificar o potencial da histologia em identificar processos vitais em ossos putrefeitos sem tecidos moles; um controle negativo foi incluído (fratura post-mortem). Os resultados mostraram a presença de coágulos e resíduos de eritrócitos nas margens fraturadas em vida, indicando fortemente reação vital ${ }^{14}$.

O diagnóstico da vitalidade da lesão, assim como a determinação do tempo decorrido entre a produção da lesão e a morte, é uma questão crucial na patologia forense. A coloração vermelho-púrpura (infiltração hemorrágica) de um corte ou hematoma irá revelar sua vitalidade, enquanto a mudança na coloração (espectro equimótico), de uma perspectiva macroscópica, irá revelar o tempo de sobrevivência. É recomendável que sempre seja feita a análise microscópica para corroborar os achados a olho nu ${ }^{14}$

Este estudo mostra que pode ser válido persistir no estudo de fraturas ósseas do ponto de vista histopatológico mesmo em um "osso seco" para verificar se a fratura foi ou não vital e, caso tenha sido, se o tempo em que se deu o trauma pode ser verificado ${ }^{14}$.

Atualmente, no caso dos ossos secos, só se poderá diagnosticar a lesão como fratura "perimortem" - sem especificar se foi exatamente ante ou post-mortem, o que seria pouco antes ou pouco após a morte; a fratura só poderá ser descrita como certamente antemortem se houver sinais de cura. O início do processo, como a produção periosteal e a formação de calo, podem ser detectados tanto macroscopicamente quanto radiologicamente (não antes de 10 ou 14 dias após a lesão) ${ }^{14}$.

$\mathrm{Na}$ fratura com maior tempo de sobrevivência do estudo ${ }^{14}, 26$ dias, havia sinais macroscópicos de cura nas margens. Nas outras fraturas (tempos entre 0 e 19 dias), as margens não apresentavam nenhuma variação macroscópica, ou seja, a olho nu seriam avaliadas como fraturas perimortem $^{14}$.

Histologicamente, pode-se ver nova formação óssea na lesão ocorrida 19 dias antes da morte; coágulos sanguíneos sugestivos de depósito de fibrina nas margens das fraturas ocorridas 16 e 26 dias antes; deposição de fibrina nas que ocorreram 8,5 horas e 5 dias antes; e um pequeno coágulo sanguíneo na lesão ocorrida 34 minutos antes da morte ${ }^{14}$. Desta forma, observa-se neste estudo que a análise histopatológica é imprescindível, e não somente a observação macroscópica da fratura ${ }^{14}$.

Do ponto de vista da análise anatomopatológica celular, a morte das células não ocorre imediatamente após o estímulo hipóxico inicial e torna-se evidente apenas depois de certo tempo. Desta forma, o diagnóstico post-mortem do infarto agudo do miocárdio (IAM) é problemático, especialmente nos casos em que a morte ocorreu logo após (entre minutos a horas) o início da isquemia miocárdica. As primeiras alterações histológicas relacionadas ao dano miocárdico (hipereosinofilia, ondulação de células musculares e alterações nucleares) são pouco específicas e inconclusivas. Em contraste, infiltração neutrofílica, que é um sinal mais indicativo, aparece pelo menos após 6 a 12 horas da injúria. Finalmente, o componente inflamatório crônico, tecido de granulação e depósito de colágeno aparecem mais tarde, de dias a semanas após a lesão. Assim, a fim de obter um diagnóstico histológico por meio de coloração 
Porto ACARS, Miziara ID. Dificuldades diagnósticas da causa mortis em cadáveres decompostos.

convencional (H\&E), a morte deve ocorrer pelo menos de 6 a 12 horas após o início do dano isquêmico; em muitos casos, entretanto, a morte ocorre antes deste período ${ }^{15}$.

Em geral, após o dano isquêmico inicial, ocorre uma série de alterações estruturais das proteínas do miocárdio. A este respeito, numerosos marcadores imunohistoquímicos têm sido investigados com o propósito de identificar um IAM mais precocemente; porém continua a haver um intervalo de tempo em que os marcadores imuno-histoquímicos não podem ser avaliados e, além disso, a autólise pode alterar ou influenciar a resposta imuno-histoquímica ${ }^{15}$.

$\mathrm{O}$ estudo de Barranco e Ventura ${ }^{15}$ avaliou os principais antígenos imuno-histoquímicos identificados para diagnosticar e estabelecer o IAM precoce, ou seja, aquele ocorrido com menos de seis horas de intervalo da morte. Foram eles ${ }^{15}$ :

Fibronectina: presente no plasma e na matriz extracelular. Em geral, a fibronectina é depositada precocemente no nível intracelular, devido à ruptura da membrana plasmática, e sua expressão é observável aproximadamente uma hora após o evento isquêmico. Também é positiva em casos de hipóxia global por conta de asfixia. Exibiu expressão imuno-histoquímica completa em casos de intervalo post-mortem de 3 a 4 $\operatorname{dias}^{15}$

C9: sua positividade permanece relativamente constante, durando até dez dias após a morte, mesmo quando os fenômenos iniciais de putrefação instalaram- $\mathrm{se}^{15}$.

C5B9: produto final da cascata de complemento, causa necrose celular por meio da formação de poros na superfície celular. Sua presença nas células indica a conclusão do processo lítico do complemento. Em geral, sua expressão é muito recente, e detectável imunohistoquimicamente 40 minutos após a morte, aproximadamente. É bastante resistente à putrefação e pode ser detectado até onze dias post-mortem; entretanto, alguma alteração em sua expressão imuno-histoquímica já é perceptível dois a três dias após a morte e sua completa alteração, após cerca de uma semana ${ }^{15}$.

Mioglobina: sua alteração imuno-histoquímica ocorre após 30 a 60 minutos. Não há muitas evidências de seu comportamento frente a fenômenos autolíticos e putrefativos. Foi descrita uma resistência genérica da expressão imuno-histoquímica por cerca de dois a três dias após a morte ${ }^{15}$.

H-FABP: sua depleção mostrou-se observável em amostras de necrópsia até 60 horas após a morte ${ }^{15}$.

Caspase-3: expressão imuno-histoquímica recente. A reação não se encontrava marcadamente comprometida pelo fenômeno autolítico ${ }^{15}$.

Fibrinogênio: proteína de fase aguda e fator de coagulação. A expressão se dá cedo, 30 minutos após a lesão isquêmica, e declina com o início da putrefação ${ }^{15}$.

Junção aderente 1 (ZO-1): marcadamente suscetível ao fenômeno putrefativo ${ }^{15}$.

S100: sua depleção foi observada no evento da isquemia miocárdica recente ${ }^{15}$.

HIF-1: marcador extremamente suscetível ao fenômeno autolítico putrefativo ${ }^{15}$.

Distrofina: uma análise imuno-histoquímica experimental revelou sua depleção pouco tempo após o IAM. O impacto da putrefação em sua expressão não foi completamente investigado ${ }^{15}$.

Galectina: expressão ocorre 30 minutos após a isquemia inicial. Não há detalhes do impacto da putrefação neste marcador ${ }^{15}$.

Troponina: ausência de dados consistentes ${ }^{15}$.

Ditirosina: ausência de dados envolvendo putrefação ${ }^{15}$.

IL-15 e monócito quimiotático proteína-1 (MCP-1): sem informações sobre a influência imunohistoquímica do intervalo post-mortem e da putrefação ${ }^{15}$. Jun-B: a resistência à putrefação não foi avaliada ${ }^{15}$. Cx43/np-Cx43: sua resistência ao fenômeno putrefativo não foi completamente investigada ${ }^{15}$.

SORBS2: não há avaliação completa a respeito do fenômeno autolítico ${ }^{15}$.

Proteínas citoesqueléticas (desmina, vinculina, $\alpha$-actina): o impacto da putrefação nestes marcadores não está claramente definido ${ }^{15}$.

O grau de autólise e putrefação das peças, o método de fixação, sua duração, o período de incubação e a concentração de anticorpos são fatores-chave que interferem no resultado da análise imuno-histoquímica. A autólise e a consequente putrefação causam a quebra dos tecidos, com degeneração das estruturas proteicas resultantes da ativação da enzima promovida pela acidose. Sendo assim, a resistência dos marcadores imuno-histoquímicos utilizados deve ser sempre referida ao estado de putrefação do cadáver, e não apenas ao intervalo post-mortem, por conta das condições ambientais e da preservação do corpo ${ }^{15}$.

Outra grande dúvida que surge durante a investigação do corpo em putrefação é o achado de etanol. Para auxiliar este quadro, a determinação de Etil Glicuronídeo (EtG) nos materiais biológicos é importante, uma vez que permite excluir a formação postmortem de etanol iniciado por muitos micro-organismos, incluindo Escherichia coli, durante a putrefação, frente a uma possível ingestão em vida ${ }^{16}$.

Etil Glicuronídeo (EtG), sendo um metabólito direto do etanol, pode ser usado como marcador altamente específico para avaliar a ingestão de álcool a médio prazo. EtG é uma molécula não volátil polar, relativamente estável. Ela deriva da conjugação do etanol com ácido glicurônico ativado através da mediação do UDP-glicuronil transferase (UGT) no retículo endoplasmático dos hepatócitos. Apenas 0,02-0,06\% do etanol ingerido é transformado em EtG. O consumo 
de uma quantidade de etanol capaz de determinar um nível de álcool de $0,50 \mathrm{~g} / \mathrm{kg}$ é suficiente para resultar na formação de $\mathrm{EtG}$, que pode ser detectado no sangue após quatro horas de ingestão, e permanece no corpo por até 14 horas. Nas análises post-mortem de álcool, a matriz mais comumente utilizada é o sangue; porém é sabido que o sangue é suscetível a alterações post-mortem. Para superar esta limitação, o uso de uma matriz complementar ao sangue é de grande relevância forense. O humor vítreo tem um caráter líquido e resiste à putrefação, o que o torna atrativo para análises quantitativas em casos que o sangue não está disponível ou está deteriorado ${ }^{16}$.

No estudo de Vezzoli et al. ${ }^{16}$, foram retiradas 63 amostras de sangue da veia femoral e humor vítreo, dentro de 48 horas após a descoberta da morte. As amostras foram sujeitas a análise para detectar EtG; os resultados foram posteriormente comparados com as quantidades de etanol em ambas as matrizes para obter mais informações sobre o consumo de álcool. Além disso, dois importantes marcadores de putrefação foram avaliados no sangue do cadáver, aldeído acético (etanal ou acetaldeído) e n-propanol, produzidos por processo fermentativo postmortem, com o objetivo de descobrir se a fonte de etanol do sangue era de natureza putrefativa ${ }^{16}$.

Casos de etanol com concentração sanguínea entre $0,49-0,56 \mathrm{~g} / \mathrm{kg}$, mas com concentração sanguínea de EtG menor ou igual ao limite inferior de quantificação, provavelmente indicam uma neoformação post-mortem de etanol. Em casos em que a ingesta de álcool etílico não pode ser claramente traçada apenas por correspondência com o dado do EtG detectado nos fluidos biológicos examinados, pode ser pertinente avaliar outros parâmetros como n-propanol e acetaldeído que, em altas concentrações, podem ser bons indicativos de suspeita putrefação ${ }^{16}$.

\section{DISCUSSÃO}

A putrefação cadavérica é um fenômeno destrutivo que tem seu início com o aparecimento da mancha verde abdominal, em torno de 24 horas após o óbito. A partir deste evento putrefativo inicial, seguem-se fases que estão muito bem descritas na literatura médico-legal disponível nos dias de hoje - como pudemos constatar na leitura das obras dos autores consagrados da Medicina Legal brasileira ${ }^{1-6}$. Todos estes autores são concordes que os eventos progridem às custas da ação de bactérias intestinais que produzem, por processos bioquímicos, gases putrefativos que vão influir diretamente no formato do corpo a ser examinado e na aparência de lesões infligidas ao corpo.

Estas alterações de forma do corpo e das lesões porventura recebidas são as principais responsáveis pelas dificuldades geradas para que o investigador chegue a uma conclusão a respeito da causa mortis do indivíduo no cadáver consumido pelos fenômenos putrefativos. Quanto mais tempo transcorre entre a data da morte e a data do exame cadavérico, maior será essa dificuldade diagnóstica ${ }^{1-5}$.

É importante notar que tais fases citadas anteriormente podem ou não ter seus cursos alterados, sendo dependentes de variáveis contributivas ou modificadoras, como o meio ambiente em que o cadáver se encontra com temperatura, umidade, solo e fauna próprios, e os fatores intrínsecos que o indivíduo carregava em vida ${ }^{1-5}$, como sua compleição física e ausência ou presença de comorbidades ${ }^{1-3}$.

Lembremos, como afirma França ${ }^{2}$, que apesar de todas essas alterações causadas pelo processo putrefativo, sempre é possível distinguir por meio de estudos bioquímicos/toxicológicos a presença de elementos estranhos aos mecanismos de putrefação. $\mathrm{O}$ autor cita, por exemplo, encontrar-se arsênico em um corpo putrefeito, fato que, certamente, é oriundo de causa outra que não a marcha putrefativa e conclui, de maneira acertada que, apesar de o corpo estar em condições de transformação destrutiva avançada, é imperiosa, para melhor diagnóstico da causa mortis, a coleta de material para exames toxicológicos, não se aceitando justificativa em contrário ${ }^{2}$.

De acordo com estes estudos citados, o meio ambiente tem influência preponderante, tanto na destruição/putrefação, quanto na conservação do cadáver. Grosso modo, pode-se afirmar que altas temperaturas aceleram o processo destrutivo, ainda que um fenômeno como a mumificação ocorra em ambientes secos e com temperaturas elevadas ${ }^{1-6}$.

Já a compleição física mais robusta ante-mortem é também responsável pela putrefação mais rápida. A explicação para tal evento reside na maior quantidade de tecido gorduroso e/ou edema a ser consumido pela microbiota bacteriana ${ }^{1,2,4}$; assim como a presença de comorbidades do tipo consumptivas, como $\mathrm{sepse}^{4}$, câncer e diabetes mellitus ${ }^{2}$, que também aceleram a decomposição.

Nota-se, ao estudar tais autores, que o Brasil já experimentou décadas de intenso estudo e inovação na área da tanatologia, e vem caminhando há alguns anos para a estagnação.

O objetivo especial contou como base a pesquisa em artigos científicos que abordassem as dificuldades que a decomposição de um corpo impõe na determinação de sua causa mortis e reconhecimento, e o que há de mais recente para transpor alguns dos obstáculos encontrados. Os artigos foram em sua totalidade estrangeiros, de países onde necrópsias em cadáveres decompostos são realizadas, sempre norteadas pela busca de facilitadores para que o maior número possível de questões possa ser respondido.

É comum pensar que um cadáver decomposto 
ofereça mais perguntas do que respostas. Com a análise de tais artigos, nota-se que sempre vale a pena explorar o máximo possível destas necrópsias ${ }^{9}$, independentemente de o cadáver ter estado em ambiente aberto, exposto à ação da fauna local ${ }^{7}$, ou se fora encontrado em ambiente aquático ${ }^{8}$. Com a aplicação de técnicas adequadas de histopatologia e imuno-histoquímica, até mesmo o que havia de mais oculto em um cérebro decomposto é revelado ${ }^{13}$. Também torna-se possível analisar com maior precisão o tempo de ocorrência de lesões e fraturas ${ }^{14}$, assim como condições crônicas de saúde ${ }^{15}$, possibilitando verificar se existem ou não correlações entre tais quadros e a morte. A análise de fluidos como o humor vítreo, mais resistente à putrefação, pode ainda revelar se houve ou não neoformação de compostos como o etanol, podendo também incluir ou excluir hipótese de correlação com a ingesta de substâncias e a morte ${ }^{16}$. Dentre os cuidados à saúde há uma importante ferramenta diagnóstica que também se revelou preciosa para o estudo post-mortem: os métodos de imagem. Eles podem ser valiosos para diferenciar estruturas ou supostas lesões vitais daquelas pós-mortais ${ }^{12}$. Até mesmo as hipóstases avaliadas a olho nu podem ganhar uma análise mais precisa quando se combinam a alguns instrumentos, revelando dados mais assertivos a respeito do tempo de morte ${ }^{11}$.

Entretanto, o que não se pode descartar, mesmo com inovações tecnológicas, é a análise macroscópica cuidadosa da equipe forense. Um olhar atento consegue mudar o rumo de investigações, a exemplo citado: podese depreender que incisões simétricas, semelhantes a lesões ritualísticas, analisadas juntamente ao histórico de saúde do indivíduo e a uma busca mais detalhada durante a necrópsia, refiram-se a incisões cirúrgicas, concluindo-se tratar-se de uma morte resultante de complicações de uma condição crônica ${ }^{10}$, não envolvendo nenhum tipo de crime e modificando as estatísticas.

A decomposição do corpo é causadora de muitos problemas durante sua avaliação post-mortem, e devido à natureza desagradável dos corpos putrefeitos, estes casos tendem a ser tratados de forma negligente quando comparados a corpos mais preservados. O levantamento bibliográfico exposto mostra que vale a pena realizar a necrópsia destes casos, e com ainda mais cautela. A necrópsia de um cadáver em decomposição deve sempre ser estudada e bem realizada.

\section{CONCLUSÃO}

Do exposto, concluímos que:

1) A marcha da decomposição, em especial a putrefação, altera as lesões e as características do corpo, portanto dificulta a análise e a determinação da causa mortis, bem como a sua identificação;

2) Alguns métodos podem auxiliar o trabalho do médico legista, quais sejam: equipamentos de imagem, técnicas histológicas e a análise química dos fluidos e tecidos, que aliados a um treinamento adequado da equipe forense, servem para minimizar estas dificuldades.

\section{CONSIDERAÇÕES FINAIS}

O cenário da tanatologia possui bases sólidas e estudos consagrados. Entretanto, sempre haverá espaço para o uso de descobertas que, quando utilizadas por equipes competentes, trazem novas possibilidades e maior precisão a um trabalho tão importante e fundamental para que se entenda como vive - e morre - uma população.

Porto ACARS, Miziara ID. Diagnostic difficulties regarding the cause of death in decomposed cadavers. Saúde, Ética \& Justiça. 2019;24(2):57-66.

\begin{abstract}
The classical authors of Brazilian Forensic Medicine provide a solid basis for the study of cadaver decomposition. Their writings show that decomposition is subdivided in stages that occur in specific periods, which may overlap or have their course altered by factors ranging from the environment in which the corpse was found to its physique and comorbidities in life. With the specific objective of learning how to overcome these difficulties during investigations and necropsies, a literature review of scientific articles in the PubMed, Scielo and Scopus databases was carried out using the terms Putrefied, Cadaveric Putrefaction, Diagnosis and causa mortis. This resulted in ten articles on human corpses, published in English from 2000 to 2019. The literature showed that methods already known to researchers (namely, imaging equipment, histopathology, and chemical analysis of body fluids) can alter the deductions made prior to their use. However, despite all the assistance they offer, they do not replace the keen eye of a well-trained forensic team. On the contrary, they must work together. This reinforces the certainty that the necropsy of a putrefied corpse is indispensable.
\end{abstract}

KEY WORDS: Biodegradation, Environmental; Cadaver; Diagnosis; Cause of Death.

\section{REFERÊNCIAS}

1. Fávero F. Medicina Legal. $2^{\mathrm{a}}$ ed. São Paulo: Gráfica da Revista dos Tribunais; 1942.
2. França GV. Medicina Legal. $10^{\mathrm{a}}$ ed. Rio de Janeiro: Editora Guanabara Koogan LTDA; 2015. 
Porto ACARS, Miziara ID. Dificuldades diagnósticas da causa mortis em cadáveres decompostos.

3. Miziara ID. Manual Prático de Medicina Legal. $2^{\mathrm{a}}$ ed. São Paulo: Editora Atheneu; 2014.

4. Hércules HC. Medicina Legal - Texto e Atlas. $2^{\mathrm{a}}$ ed. São Paulo: Editora Atheneu; 2014.

5. Croce D, Júnior DC. Manual de Medicina Legal. $8^{\mathrm{a}}$ ed. São Paulo: Saraiva; 2012

6. Costa LRS, Costa BM. A Perícia Médico-Legal Aplicada à Área Criminal. $2^{\mathrm{a}}$ ed. Campinas: Millennium Editora; 2014.

7. Byard R, James R, Gilbert J. Diagnostic problems associated with cadaveric trauma from animal activity. Am J Forensic Med Pathol. 2002;23(3):238-44. DOI: http://dx.doi. org/10.1097/00000433-200209000-00006

8. Lunetta P, Penttilä A, Sajantila A. Circumstances and macropathologic findings in 1590 consecutive cases of bodies found in water. Am J Forensic Med Pathol. 2002;23(4):3716. DOI: http://dx.doi.org/10.1097/00000433-20021200000015

9. Maujean G, Vacher P, Bagur J, Guinet T, Malicier D. Forensic autopsy of human decomposed bodies as a valuable tool for prevention: a French regional study. Am J Forensic Med Pathol. 2016;37(4):270-4. DOI: http://dx.doi.org/10.1097/ PAF.0000000000000266

10. Byard R, Gehl A, Anders S, Tsokos M. Putrefaction and wound dehiscence: a potentially confusing postmortem phenomenon. Am J Forensic Med Pathol. 2006;27(1):61-3. DOI: http:// dx.doi.org/10.1097/01.paf.0000202708.49030.03

11. Romanelli M, Marrone M, Veneziani A, Gianciotta R,
Leonardi S, Beltempo P, et al. Hypostasis and time since death: state of the art in Italy and a novel approach for an operative instrumental protocol. Am J Forensic Med Pathol. 2015;36(2):99-103. DOI: http://dx.doi.org/10.1097/ PAF.0000000000000145

12. Levy A, Harcke H, Mallak C. Postmortem imaging: MDCT features of postmortem change and decomposition. Am J Forensic Med Pathol. 2010;31(1):12-7.

13. MacKenzie JM. Examining the decomposed brain. Am J Forensic Med Pathol. 2014;35(4):265-70. DOI: http:// dx.doi.org/10.1097/PAF.0000000000000111

14. Cattaneo C, Andreola S, Marinelli E, Poppa P, Porta $\mathrm{D}$, Grandi M. The detection of microscopic markers of hemorrhaging and wound age on dry bone: a pilot study. Am J Forensic Med Pathol. 2010;31(1):22-6. DOI: http:// dx.doi.org/10.1097/PAF.0b013e3181c15d74

15. Barranco R, Ventura F. Immunohistochemistry in the detection of early myocardial infarction: systematic review and analysis of limitations because of autolysis and putrefaction. Appl Immunohistochem Mol Morphol. 2020;28(2):95-102. DOI: http://dx.doi.org/10.1097/ PAI.0000000000000688

16. Vezzoli S, Bernini M, Ferrari F. Ethyl glucuronide in vitreous humor and blood postmortem specimens: analysis by liquid chromatography-electrospray tandem mass spectometry and interpreting results of neo-formation of ethanol. Ann Ist Super Sanita. 2015;51(1):19-27. DOI: http://dx.doi. org/10.4415/ANN_15 0105 